University of Nebraska - Lincoln

DigitalCommons@University of Nebraska - Lincoln

USDA Wildlife Services - Staff Publications

U.S. Department of Agriculture: Animal and Plant Health Inspection Service

2008

Livestock Protection Dogs for Deterring Deer From Cattle and Feed

Kurt C. Vercauteren

USDA-APHIS-Wildlife Services, kurt.c.vercauteren@usda.gov

Michael J. Lavelle

USDA/APHIS/WS National Wildlife Research Center, michael.j.lavelle@aphis.usda.gov

Gregory Phillips

USDA-APHIS-Wildlife Services

Follow this and additional works at: https://digitalcommons.unl.edu/icwdm_usdanwrc

Part of the Environmental Sciences Commons

Vercauteren, Kurt C.; Lavelle, Michael J.; and Phillips, Gregory, "Livestock Protection Dogs for Deterring Deer From Cattle and Feed" (2008). USDA Wildlife Services - Staff Publications. 986.

https://digitalcommons.unl.edu/icwdm_usdanwrc/986

This Article is brought to you for free and open access by the U.S. Department of Agriculture: Animal and Plant Health Inspection Service at DigitalCommons@University of Nebraska - Lincoln. It has been accepted for inclusion in USDA Wildlife Services - Staff Publications by an authorized administrator of DigitalCommons@University of Nebraska - Lincoln. 


\title{
Livestock Protection Dogs for Deterring Deer From Cattle and Feed
}

\author{
KURT C. VERCAUTEREN, ${ }^{\mathbf{1}}$ United States Department of Agriculture, Animal and Plant Health Inspection Service, Wildlife Services, National Wildlife \\ Research Center, Fort Collins, CO 80521-2154, USA \\ MICHAEL J. LAVELLE, United States Department of Agriculture, Animal and Plant Health Inspection Service, Wildife Services, National Wildlife \\ Research Center, Fort Collins, CO 80521-2154, USA \\ GREGORY E. PHILLIPS, United States Department of Agriculture, Animal and Plant Health Inspection Service, Wildlife Services, National Wildlife \\ Research Center, Fort Collins, CO 80521-2154, USA
}

\begin{abstract}
Disease transmission between wildlife and livestock is a worldwide issue. Society needs better methods to prevent interspecies transmission to reduce disease risks. Producers have successfully used livestock protection dogs (LPDs) for thousands of years to reduce predation. We theorized that LPDs raised and bonded with cattle could be used to also reduce risk of bovine tuberculosis (Myobacterium bovis; TB) transmission between white-tailed deer (Odocoileus virginianus) and cattle by minimizing contact between the 2 species and use of cattle feed by deer. We evaluated 4 LPDs over 5 months, utilizing 2 data collection methods (direct observation and motion-activated video) on deer farms that supported higher densities than wild populations. Dogs were highly effective in preventing deer from using concentrated cattle feed (hay bales), likely the greatest risk factor of TB transmission on farms. Dogs also prevented deer from approaching cattle in core areas of pastures (near hay bales) and were very effective throughout pastures. Our research supports the theory that LPDs, specifically trained to remain with cattle, may be a practical tool to minimize potential for livestock to contract TB from infected deer in small-scale cattle operations. Where disease is present in deer, it may be possible to reduce the potential for disease transmission by employing LPDs. (JOURNAL OF WILDLIFE MANAGEMENT 72(6):1443-1448; 2008)
\end{abstract}

DOI: $10.2193 / 2007-372$

KEY WORDS bovine tuberculosis, disease, exclusion, livestock protection dog, Odocoileus virginianus, white-tailed deer, wildlife damage management.

Bovine tuberculosis (Mycobacterium bovis; TB) occurs in wild white-tailed deer (Odocoileus virginianus) in the northeastern portion of Michigan's Lower Peninsula, USA. White-tailed deer are considered the primary reservoir and maintenance host of TB in the area and have been implicated for infecting cattle there (Palmer et al. 2001; O'Brien et al. 2002, 2006). Palmer et al. (2004) demonstrated that infected deer are capable of transmitting TB to cattle indirectly through shared feed, and O'Brien et al. (2006) suggested feed as the primary route of transmission from deer to cattle. Transmission can also occur directly from animal to animal through aerosol, saliva, and nasal secretions (Palmer et al. 1999). To minimize direct and indirect transmission of TB from infected deer to cattle, we need effective on-farm methods to reduce deer activity near cattle.

Dog breeds such as Great Pyrenees, Kuvasz, Komondor, Akbash, and Anatolian have been used for $>2,000$ years to stay with and control predation on sheep and other livestock in Europe (Coppinger and Coppinger 2001). Previous studies reported that livestock protection dogs (LPDs) occasionally chased deer (Odocoileus spp.; Coppinger et al. 1988, Green and Woodruff 1999) and reindeer (Rangifer tarandus; Hansen and Bakken 1999). An interest in deer, combined with their affinity to livestock, suggested to us that LPDs could keep deer from contacting cattle and cattle feed, thereby reducing potential for deer to transmit TB to cattle.

Our literature review and personal communications

${ }^{1}$ E-mail: kurt.c.vercauteren@aphis.usda.gov revealed no research testing the efficacy of dogs for excluding deer or other non-predatory species from areas used by cattle or other livestock. However, dogs have been used to protect diverse resources such as forest plantations (Beringer et al. 1994), golf courses (Woodruff and Green 1995), office complexes (Castelli and Sleggs 2000), orchards (R. P. Coppinger, Hampshire College, unpublished report; Curtis and Rieckenberg 2005), and vegetable farms (VerCauteren et al. 2005) from a variety of wildlife. Because of their usefulness at similar tasks, we theorized that we could train LPDs to repel deer from specific areas or situations.

Breeds of LPDs vary greatly in 3 overlapping behaviors: trustworthiness, attentiveness, and protection of livestock (Coppinger et al. 1983, 1987; Andelt 1999). An effective LPD typically has a balance of these behaviors and should investigate and confront intruders aggressively (Jenkins 2003). Livestock producers believe the Great Pyrenees is effective for protecting livestock (Green and Woodruff 1988), an economic asset (Green and Woodruff 1988), minimally aggressive towards people (Green et al. 1984, Green and Woodruff 1990, Hansen and Bakken 1999), and less likely to harm livestock than are other breeds of LPDs (Green and Woodruff 1988, Hansen and Bakken 1999). Great Pyrenees also exhibit signs of behavioral maturity at an earlier age (12-18 months) than other breeds (18-36 months; Green and Woodruff 1999, Jenkins 2003). Therefore, we determined Great Pyrenees were best suited for our nontraditional application.

Our goal was to determine if LPDs, raised and bonded 


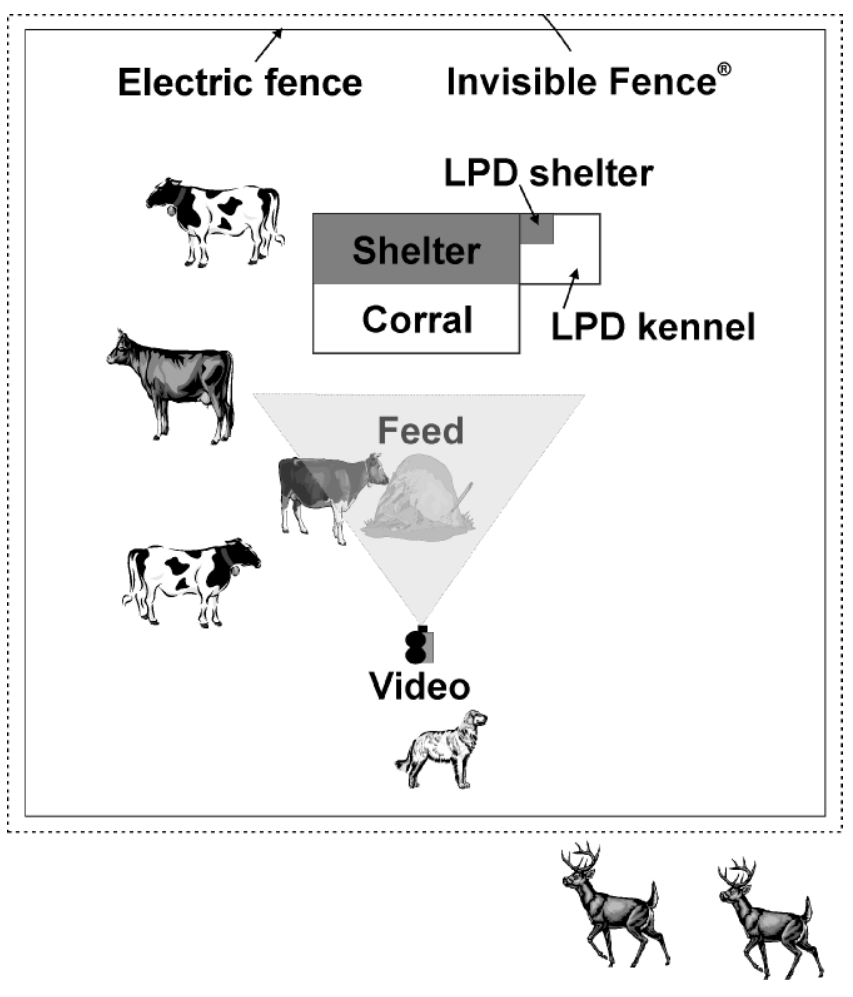

Figure 1. Experimental pastures (1.2 ha each) to evaluate efficacy of livestock protection dogs (LPDs) for preventing contact between whitetailed deer and cattle or cattle feed at study sites in the northeastern Lower Peninsula of Michigan, USA, March-August 2003.

with calves, could reduce direct and indirect contact between white-tailed deer and cattle. We predicted LPDs would reduce number of deer entering cattle pastures, reduce use of concentrated cattle feed by deer, and reduce occurrence of deer approaching cattle to within a 5-m radius of potential aerosol transmission of TB.

\section{STUDY AREA}

We evaluated LPDs on 2 privately owned white-tailed deer facilities with unnaturally high densities of deer in the northeastern portion of the Lower Peninsula of Michigan. The sites were high-fence hunting enclosures and they were $40 \mathrm{~km}$ apart. Our study sites were within the 4-county area (Alpena, Alcona, Montmorency, and Oscoda counties) where TB is established in free-ranging deer (O'Brien et al. 2006). One site enclosed 72.2 ha and the other enclosed 153.9 ha. Sites consisted of similar habitat: mixed lowland conifer-hardwoods, ephemeral wetland-wet meadow, oak (Quercus spp.) upland forest, and other broad-leaved deciduous forest, and contained food plots for deer. Summer temperature averaged $23^{\circ} \mathrm{C}$, winter temperature averaged $-5^{\circ} \mathrm{C}$, and annual precipitation ranged from $70 \mathrm{~cm}$ to 90 cm (Ruffner and Bair 1987).

Deer densities at our study sites were much higher than typical densities of free-ranging white-tailed deer. We conducted informal road count surveys at each site, resulting in estimated densities of approximately $90 \mathrm{deer} / \mathrm{km}^{2}$ and 240 deer $/ \mathrm{km}^{2}$ at our study sites compared to $19-23 \mathrm{deer} / \mathrm{km}^{2}$ for wild deer populations in northern Michigan at the outset of the TB epidemic (Schmitt et al. 1997, Palmer et al. 2001). To estimate densities, we conducted surveys on 3 consecutive nights in early April by methodically traversing the road systems on the properties and counting deer with the aid of forward-looking infrared (FLIR) thermal-imaging devices (Nightsight $^{\mathrm{TM}}$, PalmIR 250 Digital; Raytheon Commercial Infrared, Dallas, TX). We derived our density estimate from the mean of the 3 surveys. Our estimates were conservative because we conducted surveys prefawning and because, though our presence did not motivate deer to flee and possibly be counted more than once, it is likely that we could not see every deer from the roads. Our density estimates corroborated with those of the owners of the deer facilities. We selected such high-density sites to provide a severe test of efficacy of LPDs for deterring deer.

\section{METHODS}

\section{Selection and Training of Dogs}

One year before initiating the study, we purchased 4 newborn Great Pyrenees pups (3 F, $1 \mathrm{M}$ ) from reputable breeders that were willing and capable of raising and training pups with calves. We followed recommendations of breeders and other researchers (Black and Green 1985, Green and Woodruff 1999, Hansen and Bakken 1999, Hansen and Smith 1999, Andelt 2001) and isolated the LPDs from littermates at 8 weeks of age. For the next 6 weeks, we penned each LPD immediately adjacent to 2-4 $<1$-week-old calves and allowed them in a $3 \times 5$-m corral with the calves for several hours each day. When LDPs were 3.5 months of age, we placed them with their calves continuously, providing an area with feed and bedding accessible only to the LPD.

We began active training of LPDs at 6 months to encourage establishment of territory and exploration within 0.4-ha pastures. We allowed LPDs and calves to spend time in progressively larger pastures $(0.5-1.2 \mathrm{ha})$. If an LPD played aggressively with the calves, we reprimanded it immediately. We spayed and neutered LPDs at this time to minimize potential problems with roaming. Throughout training, we limited human contact to encourage LPDs to bond strongly with calves rather than with people.

One month before introducing calves and LPDs to the study sites, we established 4 1.2-ha pastures on each deer facility (Fig. 1). The perimeter of each pasture was $440 \mathrm{~m}$, consisting of a $0.75-\mathrm{m}, 2$-strand electric poly-rope fence to contain the calves and Invisible Fence ${ }^{\circledR}$ wire (IFCO Enterprises, Malvern, PA) to contain the LPD. We spaced pastures $>200 \mathrm{~m}$ apart to ensure activity at one pasture would not affect another. Thick wooded cover prevented seeing one pasture from another, and activity from one pasture could rarely be heard from another. We provided whole-kernel corn and alfalfa at the center of each pasture to encourage deer use. At $10 \mathrm{~m}$ away from feed, we constructed 3 -sided shelters and $5 \times 5-\mathrm{m}$ corrals for calves and kennels with 3-sided shelters for LPDs.

When they were 11 months of age, we randomly assigned and introduced LPDs (and the same 2-4 calves with which 
they were raised) to pastures. At each site, 2 pastures were protected (contained an LPD) and 2 were unprotected (contained no LPD). We also added similar-aged calves to each pasture, so that each contained 4 calves. For the first 2 weeks after introduction, we housed LPDs in the corral with the calves during the day and kenneled them adjacent to the corral at night. We also began conducting Invisible Fence training under the guidance of Invisible Fence professionals. The fence system consisted of a transmitter that emitted a radio signal from a wire that acted as a boundary for LPDs, which were wearing shock collars. When an LPD approached within $1 \mathrm{~m}$ of the wire, the collar emitted an audible signal followed by a shock unless the LPD quickly retreated.

After this 2-week period, we allowed LPDs and calves to roam freely within their pastures. When we observed deer while with an LPD, we encouraged a rapid and enthusiastic approach toward the deer. We continued to use the established feed area at the center of each pasture for cattle feed throughout the study. Food, shelter, and water were always accessible to LPDs and calves, and we routinely examined them and provided veterinarian care when needed. We fed dogs commercially available dog chow.

\section{Pasture Study to Evaluate Effects of LPDs}

Before initiating data collection, we provided a 2-week period with minimal human activity to allow deer to acclimate. At this point, the LPDs were approximately 1 year old. We evaluated LPDs' effects on deer from 6 March 2003 through 15 August 2003. At the end of May, we randomly reassigned individual dogs to previously unprotected pastures within the same site (crossover design) to minimize potential for bias caused by differences among pastures (Fig. 2). Although we began data acquisition immediately after the crossover, we graphically evaluated potential for treatment in period 1 to carry over into period 2 , that is, the potential for reduced deer activity in control pastures during period 2 caused by prior presence of LPDs in period 1 (carryover effect).

We used direct observation and motion-activated video to acquire data on deer intrusions into cattle pastures. We conducted direct observations 1-2 times per week per pasture and observation periods took place from 2 hours before to 2 hours after sunset. We collected data with binoculars, night-vision optics, and FLIR from ground and elevated blinds. We installed color-coded stakes at 5-m intervals radiating out from each central feeding site in the 4 cardinal directions to facilitate distance estimates.

We installed one video system per pasture to sample and record deer activity in pasture centers near spatially concentrated feed (hay bales; Fig. 1). Video systems consisted of programmable data loggers and passive infrared sensors (Trailmaster ${ }^{\circledR}$ TM 700v; Goodson \& Associates, Inc., Lenexa, KS) that activated video cameras (Sony Handycam ${ }^{\circledR}$; Sony Corporation, Tokyo, Japan) and redfiltered lights. Camera footage was recorded when passive infrared sensors detected body heat in motion. We programmed video systems to be on every other night from

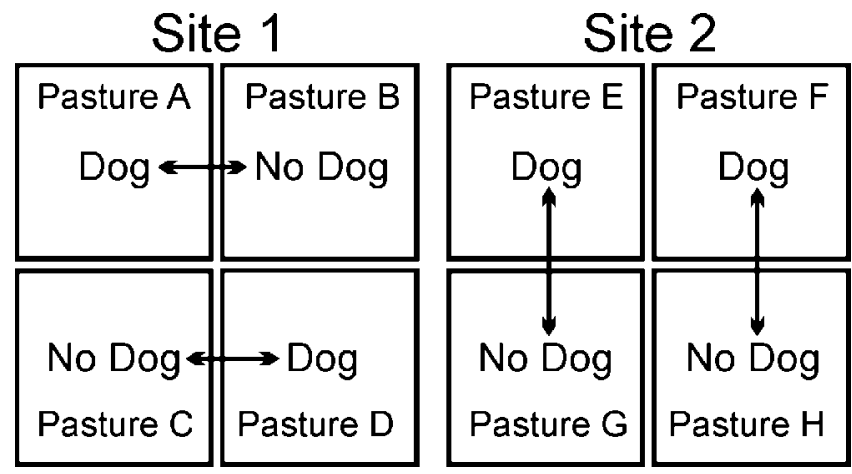

Figure 2. Study design to evaluate efficacy of livestock protection dogs (LPDs) for preventing contact between white-tailed deer and cattle or cattle feed at study sites in the northeastern Lower Peninsula of Michigan, USA, March-August 2003. One of 2 periods is shown, with double-headed arrows indicating randomly allocated crossover of treatments between periods. Each pasture contained 4 calves and Dog pastures contained 1 LPD trained to deter deer from entering pastures and from approaching cattle and cattle feed.

0.5 hours before sunset to 0.5 hours after sunrise and record as long as they sensed activity and videotape space was available. We set lenses on cameras to the full wide-angle setting and focused them on the feed from $10 \mathrm{~m}$ to the south.

We recorded time, date, and number of deer entering the pasture (direct observation) or camera field of view. For each deer observed within a pasture, we recorded minimum distance from cattle, duration of time $\leq 5 \mathrm{~m}$ from cattle, whether deer consumed cattle feed, and amount of time spent consuming it. We adopted a distance of $\leq 5 \mathrm{~m}$ as a reasonable criterion for potential aerosol transmission of $\mathrm{TB}$ between deer and cattle. Although a distance for aerosol transmission of TB has not been established for deer or other large mammals, research on ferrets (Mustela furo; Sauter and Morris 1995) and Australian brushtail possums (Trichosurus vulpecula; O'hara et al. 1976, Sauter and Morris 1995) suggests possible aerosol transmission at $<5 \mathrm{~m}$. The United States Department of Agriculture (USDA)-Animal and Plant Health Inspection Service-Wildlife ServicesNational Wildlife Research Center's Institutional Animal Care and Use Committee approved all procedures.

\section{Analyses}

We identified 2 response variables from direct observation data for evaluating differences in deer activity between pastures protected by LPDs (Dog) and unprotected pastures (No Dog). We standardized counts of deer seen in pastures for differences in sampling effort creating a continuous variable $P=\sum$ (count) $/ \sum$ (hr of observation), where summation occurred over each pasture $X$ period combination. We similarly standardized counts of events where $\geq 1$ deer per group approached to $\leq 5 \mathrm{~m}$ from cattle per hour of observation $(C)$. We used video data to quantify one additional variable relating to deer use of hay: number of events per hour of recorded video where $\geq 1$ deer per group used cattle feed $(H)$. We considered $C$ an index of direct disease transmission risk, $H$ an index of indirect trans- 
Table 1. Model selection results for response variables evaluating efficacy of livestock protection dogs for preventing contact between white-tailed deer and cattle or cattle feed at study sites in the northeastern Lower Peninsula of Michigan, USA, March-August 2003.

\begin{tabular}{|c|c|c|c|c|c|c|}
\hline Response variable $^{a}$ & Model $^{\text {b }}$ & Log-likelihood & No. parameters & $\mathrm{AIC}_{c}^{\mathrm{c}}$ & $\Delta \mathrm{AIC}_{c}$ & $w_{i}^{\mathrm{d}}$ \\
\hline \multirow[t]{4}{*}{$\Delta_{P}$} & Intercept & -9.69 & 2 & 25.78 & 0.00 & 0.887 \\
\hline & Site & -9.64 & 3 & 31.28 & 5.50 & 0.057 \\
\hline & Order & -9.64 & 3 & 31.28 & 5.50 & 0.057 \\
\hline & $\operatorname{Dog}($ Site $)$ & -9.44 & 5 & 58.88 & 33.10 & $<0.001$ \\
\hline \multirow[t]{4}{*}{$\Delta_{C}$} & Intercept & 9.19 & 2 & -11.98 & 0.00 & 0.868 \\
\hline & Site & 9.60 & 3 & -7.20 & 4.78 & 0.084 \\
\hline & Order & 9.19 & 3 & -6.38 & 5.60 & 0.056 \\
\hline & $\operatorname{Dog}($ Site $)$ & 11.08 & 5 & 17.85 & 29.83 & $<0.001$ \\
\hline \multirow[t]{4}{*}{$\Delta_{H}$} & Intercept & -2.68 & 2 & 11.75 & 0.00 & 0.887 \\
\hline & Site & -2.61 & 3 & 17.21 & 5.46 & 0.058 \\
\hline & Order & -2.66 & 3 & 17.31 & 5.56 & 0.055 \\
\hline & $\operatorname{Dog}($ Site $)$ & -1.91 & 5 & 43.82 & 32.07 & $<0.001$ \\
\hline
\end{tabular}

\footnotetext{
${ }^{\mathrm{a}} \Delta_{P}=$ control-treatment (No Dog-Dog) difference in no. of deer seen in experimental cattle pastures/hr of visual observation, $\Delta_{C}=$ No Dog-Dog difference in no. of events/hr of visual observation where $\geq 1$ deer/group approached to $\leq 5 \mathrm{~m}$ from cattle, $\Delta_{H}=$ No Dog-Dog difference in no. of events/hr of recorded video where $\geq 1$ deer/group fed from concentrated cattle feed (hay).

${ }^{\mathrm{b}}$ All models included an intercept plus additive terms shown.

'Akaike's Information Criterion adjusted for sample size.

${ }^{\mathrm{d}} \mathrm{AIC}_{c}$ wt.
}

mission risk via contamination of a spatially concentrated feed source, and $P$ an index of indirect transmission risk via a dispersed feed source (i.e., pasture grass).

Our analysis objective was to estimate treatment effects of LPDs while evaluating effects of period and site. Period effects could result from plant and deer phenology, repeated measures on experimental units (pastures) leading to correlated data and biased variance estimates, and carryover effects of treatment causing biased (low) estimates of treatment effect. Our use of crossover provided 2 paired (within-pasture) comparisons per LPD involving 2 pastures per LPD, where treatment preceded control in one pasture and control preceded treatment in the other pasture. To minimize effects of correlated responses and betweenpasture variation, we used paired (within-pasture) differences between treatment and control levels of $P, C$, and $H$ $\left(\Delta_{P}, \Delta_{C}\right.$, and $\Delta_{H}$, respectively) as response variables for analyses. Crossover minimized influence of seasonal phenology but created potential for LPD treatment carryover effect, wherein presence of an LPD in a pasture in period 1 might reduce numbers of deer entering that pasture in period 2. We used a predictor variable that coded for treatment order (order) to evaluate evidence of treatment carryover between periods.

We used PROC GLIMMIX (SAS Institute, Cary, NC) to fit models for $\Delta_{P}, \Delta_{C}$, and $\Delta_{H}$ using the normal distribution and identity link. We used informationtheoretic methods adjusted for sample size to evaluate strength of evidence among 4 models for each response variable (Burnham and Anderson 2002). We used maximum likelihood for model selection and restricted maximum likelihood to refit models for estimating treatment effects to minimize bias in variance estimation (Littell et al. 2006). Because our sample was small ( $n=8$ pastures), we evaluated simple model structures to minimize numbers of estimated parameters: intercept $+\operatorname{dog}($ site ) (i.e., dog nested in site), intercept + site, intercept + order, and intercept only. We present estimates of treatment effect (model-based estimates of $\Delta_{P}, \Delta_{C}$, and $\Delta_{H}$ ) with $95 \%$ Student's $t$-based confidence intervals.

\section{RESULTS}

We accumulated 958 hours of observations at site 1, with 446 hours in period 1 (range among pastures: 109-116 hr) and 512 hours in period 2 (range: $122-135 \mathrm{hr}$ ); and 863 hours at site 2, with 417 hours in period 1 (range: 93-131 $\mathrm{hr}$ ) and 446 hours in period 2 (range: 103-120 hr). Most of the variation in cumulative observation time among pastures resulted from differences in daily observation periods caused by adverse weather conditions (range: 35-292 min). Observation time was split approximately equally between protected $(923 \mathrm{hr})$ and unprotected $(898 \mathrm{hr})$ period-pasture cells.

We recorded 1,750 hours of animal-activated video, 895 hours at protected and 855 hours at unprotected pastures. We recorded 1,007 hours at site 1, with 477 hours in period 1 (range among pastures: 108-125 hr) and 530 hours in period 2 (range: $118-140 \mathrm{hr}$ ); and 744 hours at site 2, with 347 hours in period 1 (range: $57-107 \mathrm{hr}$ ) and 397 hours in period 2 (range: $68-123 \mathrm{hr}$ ).

We found little evidence that site, order of treatment, or individual LPD influenced treatment effect for any response variable (Table 1). In all cases, confidence intervals on estimates of $\Delta_{P}, \Delta_{C}$, and $\Delta_{H}$ included zero for all models more complex than intercept-only. Intercept-only models, representing overall efficacy of LPDs, had substantial weight of evidence among candidate model sets $\left(w_{i} \geq 0.868\right.$; Table $1)$. Based on intercept-only models, LPDs reduced rates of deer entering pastures $\left(\Delta_{P},=-0.89 \mathrm{deer} / \mathrm{hr}, \mathrm{CI}:-1.62\right.$ to $-0.16 ; \bar{P}=1.39 \mathrm{deer} / \mathrm{hr}$ at unprotected pastures), deer approaching to $\leq 5 \mathrm{~m}$ from cattle $\left(\Delta_{C}=-0.083\right.$ events $/ \mathrm{hr}$, CI: -0.151 to $-0.014 ; \bar{C}=0.086$ events $/ \mathrm{hr}$ at unprotected pastures), and deer using concentrated cattle feed $\left(\Delta_{H}=\right.$ 
-0.348 events/hr, CI: -0.650 to $-0.046 ; \bar{H}=0.350$ events/ $\mathrm{hr}$ at unprotected pastures).

Our LPDs were particularly effective at protecting cattle and concentrated cattle feed. We observed only 3 cases where deer were $\leq 5 \mathrm{~m}$ from cattle in protected pastures, compared to 79 cases in unprotected pastures. Based on observation data, total time spent by deer $\leq 5 \mathrm{~m}$ from cattle was 5 minutes in protected pastures and 425 minutes in unprotected pastures. In addition, during video monitoring, we recorded no events when deer were $\leq 5 \mathrm{~m}$ from cattle in protected pastures, but we recorded 114 such events, with deer spending 292 minutes near calves, in unprotected pastures.

Similarly, we recorded only 2 events where a deer consumed hay in protected pastures, compared with 303 events in unprotected pastures. Based on video data, total duration of hay consumption by deer in protected pastures was 4.75 minutes, compared with 2,096 minutes at unprotected pastures. In addition, we detected no events of deer using hay in protected pastures during visual observations, but we detected 113 events in unprotected pastures.

\section{DISCUSSION}

Our LPDs effectively reduced direct and indirect contact with deer and cattle. The response variables we evaluated related to different potential modes of TB transmission: direct aerosol transmission due to close spatiotemporal association between potentially infected deer and uninfected cattle $\left(\Delta_{P}\right)$ and indirect transmission by temporally segregated contact with dispersed $\left(\Delta_{C}\right)$ and concentrated $\left(\Delta_{H}\right)$ feed by deer and cattle. With our unnaturally high densities of deer, we observed a high rate of deer approaching cattle in unprotected pastures $(0.093$ events/hr, or one event $/ 10.8$ hr). Direct contact between deer and cattle may be rare under typical farm conditions (e.g., one event in 1,780 hr of observation $=0.00056$ events $/ \mathrm{hr}$, Hill 2005), suggesting that potential for aerosol transmission of TB may be smaller than via concentrated feed.

The initial investment for LPDs with the training we requested ranged from $\$ 1,800$ to $\$ 3,200 / \mathrm{LPD}$ (LPD only \$500-\$700; United States currency). To evaluate the full potential of LPDs, we chose to employ qualified, reputable breeders-trainers, but costs could be considerably less for owners capable of training their own LPDs. During the first year, supervising, feeding, and training LPDs requires 7-50 hours per month, and 10-11 hours per month are required in following years (Green et al. 1984, Andelt 1992). Assuming a purchase and training cost of $\$ 2,500$, a monthly maintenance cost of $\$ 50$ (food and veterinary care), and an effective working life of up to 10 years (Green et al. 1994, Green and Woodruff 1999), the use of an LPD in our application may cost about $\$ 8,500$ or $\$ 850$ per year (2002 $\$$ ). Additional initiation and maintenance costs will be incurred associated with the fence needed to contain LPDs. We employed Invisible Fence in our study because it presented no barrier to deer while containing LPDs. One could also consider other fencing options that contain LPDs, as well as cattle (i.e., 9-strand electric fence, woven-wire sheep fence). To determine the best and most cost-effective fencing option for containing LPDs and cattle in pastures, landowners need to consider their existing infrastructure and management practices.

We were not able to determine amount of space or number of cattle an LPD can effectively protect. Our 1.2-ha pastures were large enough that LPDs were not always able to observe entire pastures and deer could enter, initially undetected, and occasionally approach cattle (4 calves/ pasture). More LPDs per pasture may increase effectiveness (Green and Woodruff 1990). Captive deer used in our study appeared highly motivated to enter protected pastures to access feed, but unprotected pastures and alternative unprotected sources of feed were always available elsewhere. Thus, we do not know how effective LPDs would be in deterring deer that were nutritionally stressed during severe winter conditions. Additionally, we do not know with certainty how performance of LPDs might change over longer times than we studied. However, our LPDs were young and LPDs usually become more effective the longer they are on the job (Green et al. 1994, Andelt and Hopper 2000).

\section{MANAGEMENT IMPLICATIONS}

Our results suggest that LPDs may reduce potential for disease transmission from deer to cattle in small pasture settings and over time spans similar to those we studied. Even in larger pastures, LPDs may effectively exclude deer from using spatially concentrated sources of cattle feed, the greatest risk factor for transmitting TB from deer to cattle. Individual cattle owners in northeastern Michigan must take greater responsibility for farm biosecurity to protect their cattle from TB infection by deer (O'Brien et al. 2006). Livestock protection dogs may provide a viable biosecurity tool, particularly for small cattle operations.

\section{ACKNOWLEDGMENTS}

We dedicate this study to R. Pooler, who passed away prior to its completion. We thank T. DeLiberto, P. Butchko, and B. Patrick for believing in our concept and facilitating the study. We are indebted to the landowners who provided us access to their properties. We thank R. Otto, R. Schenk, D. Lunning, M. Pipas, J. Gilsdorf, K. Shively, A. Aderman, J. Hill, G. Rigney, P. O'Brien, and S. Jojola for assistance in the field. M. Conner and R. Sterner provided constructive reviews of the manuscript. Mention of companies or commercial products does not imply recommendation or endorsement by the USDA.

\section{LITERATURE CITED}

Andelt, W. F. 1992. Effectiveness of livestock guarding dogs for reducing predation on domestic sheep. Wildlife Society Bulletin 20:55-62.

Andelt, W. F. 1999. Relative effectiveness of guarding-dog breeds to deter predation on domestic sheep in Colorado. Wildlife Society Bulletin 27: 706-714.

Andelt, W. F. 2001. Effectiveness of livestock guarding animals for 
reducing predation on livestock. Endangered Species UPDATE 18:182185.

Andelt, W. F., and S. N. Hopper. 2000. Livestock guard dogs reduce predation on domestic sheep in Colorado. Journal of Range Management 53:259-267.

Beringer, J., L. P. Hansen, R. A. Heinen, and N. F. Giessman. 1994. Use of dogs to reduce damage by deer to a white pine plantation. Wildlife Society Bulletin 22:627-632.

Black, H. L., and J. S. Green. 1985. Navajo use of mixed-breed dogs for management of predators. Journal of Range Management 38:11-15.

Burnham, K. P., and D. R. Anderson. 2002. Model selection and multimodel inference: a practical information-theoretic approach. Second edition. Springer-Verlag, New York, New York, USA.

Castelli, P. M., and S. E. Sleggs. 2000. Efficacy of border collies to control nuisance Canada geese. Wildlife Society Bulletin 28:385-392.

Coppinger, R., and L. Coppinger. 2001. Dogs: a startling new understanding of canine origin, behavior, and evolution. Scribner, New York, New York, USA.

Coppinger, R., L. Coppinger, G. Langeloh, L. Gettler, and J. Lorenz. 1988. A decade of use of livestock guarding dogs. Proceedings of the Vertebrate Pest Conference 13:209-214.

Coppinger, R., J. Lorenz, and L. Coppinger. 1987. New uses of livestock guarding dogs to reduce agriculture/wildlife conflicts. Proceedings of the Eastern Wildlife Damage Control Conference 3:253-259.

Coppinger, R., J. Lorenz, J. Glendinning, and P. Pinardi. 1983. Attentiveness of guarding dogs for reducing predation on domestic sheep. Journal of Range Management 36:275-279.

Curtis, P., and R. Rieckenberg. 2005. Use of dogs for reducing deer damage in apple orchards. Proceedings of the Wildlife Damage Management Conference 11:149-158.

Green, J. S., and R. A. Woodruff. 1988. Breed comparisons and characteristics of use of livestock guarding dogs. Journal of Range Management 41:249-251.

Green, J. S., and R. A. Woodruff. 1990. ADC guarding dog program update: a focus on managing dogs. Proceedings of the Vertebrate Pest Conference 14:233-236.

Green, J. S., and R. A. Woodruff. 1999. Livestock guarding dogs: protecting sheep from predators. U.S. Department of Agriculture, Agricultural Information Bulletin 588, Washington, D.C., USA.

Green, J. S., R. A. Woodruff, and W. F. Andelt. 1994. Do livestock guarding dogs lose their effectiveness over time? Proceedings of the Vertebrate Pest Conference 16:41-44.

Green, J. S., R. A. Woodruff, and T. T. Tueller. 1984. Livestock-guarding dogs for predator control: costs, benefits, and practicality. Wildlife Society Bulletin 12:44-50.

Hansen, I., and M. Bakken. 1999. Livestock-guarding dogs in Norway: part I: interactions. Journal of Range Management 52:2-6.

Hansen, I., and M. E. Smith. 1999. Livestock-guarding dogs in Norway: part II: different working regimes. Journal of Range Management 52: 312-316.
Hill, J. A. 2005. Wildlife-cattle interactions in northern Michigan: implications for the transmission of bovine tuberculosis. Thesis, Utah State University, Logan, USA.

Jenkins, D. J. 2003. Guard animals for livestock protection: existing and potential use in Australia. Vertebrate Pest Research Unit, Orange Agricultural Institute, Orange, New South Wales, Australia.

Littell, R. C., G. A. Milliken, W. W. Stroup, R. D. Wolfinger, and O. Schabenberger. 2006. SAS for mixed models. Second edition. SAS Institute, Cary, North Carolina, USA.

O’Brien, D. J., S. M. Schmitt, J. S. Fierke, S. A. Hogle, S. R. Winterstein, T. M. Cooley, W. E. Moritz, K. L. Diegel, S. D. Fitzgerald, D. E. Berry, and J. B. Kaneene. 2002. Epidemiology of Mycobacterium bovis in freeranging white-tailed deer, Michigan, USA, 1995-2000. Preventive Veterinary Medicine 54:47-63.

O'Brien, D. J., S. M. Schmitt, S. D. Fitzgerald, D. E. Berry, and G. J. Hickling. 2006. Managing the wildlife reservoir of Mycobacterium bovis: the Michigan, USA, experience. Veterinary Microbiology 112:313-323.

O'hara, P. J., A. F. Julian, and M. O. Ekdahl. 1976. Tuberculosis in the opossum (Trichosurus vulpecula): an experimental study. Pages 1-33 in Proceedings of a Seminar on Tuberculosis. Ministry of Agriculture and Fisheries, 9-14 August 1976, Hamilton, New Zealand.

Palmer, M. V., W. R. Waters, and D. L. Whipple. 2004. Investigation of the transmission of Mycobacterium bovis from deer to cattle through indirect contact. American Journal of Veterinary Research 65:1483-1489.

Palmer, M. V., D. L. Whipple, and S. C. Olsen. 1999. Development of a model of natural infection with Mycobacterium bovis in white-tailed deer. Journal of Wildlife Diseases 35:450-457.

Palmer, M. V., D. L. Whipple, and W. R. Waters. 2001. Experimental deer-to-deer transmission of Mycobacterium bovis. American Journal of Veterinary Research 62:692-696.

Ruffner, J. A., and F. E. Bair. 1987. Weather of U.S. cities. Gale Research, Detroit, Michigan, USA.

Sauter, C. M., and R. S. Morris. 1995. Behavioural studies on the potential for direct transmission of tuberculosis from feral ferrets (Mustela furo) and possums (Trichosurus vulpecula) to farmed livestock. New Zealand Veterinary Journal 43:294-300.

Schmitt, S. M., S. D. Fitzgerald, T. M. Cooley, C. S. Bruning-Fann, L. Sullivan, D. Barry, T. Carlson, R. B. Minnis, J. B. Payeur, and J. Sikarskie. 1997. Bovine tuberculosis in free-ranging white-tailed deer from Michigan. Journal of Wildlife Diseases 33:749-758.

VerCauteren, K., N. Seward, D. Hirchert, M. Jones, and S. Beckerman. 2005. Dogs for reducing wildlife damage to organic crops: a case study. Proceedings of the Wildlife Damage Management Conference 11:286293.

Woodruff, R. A., and J. S. Green. 1995. Livestock herding dogs: a unique application for wildlife damage management. Proceedings of the Great Plains Wildlife Damage Control Workshop 12:43-45.

Associate Editor: Messmer. 